\title{
CAVALCANTI, Maria Laura Viveiros de Castro. Reconhecimentos: antropologia, folclore e cultura popular. Rio de Janeiro: Aeroplano, 2012.
}

\section{Renata de Sá Gonçalves (UFF)}

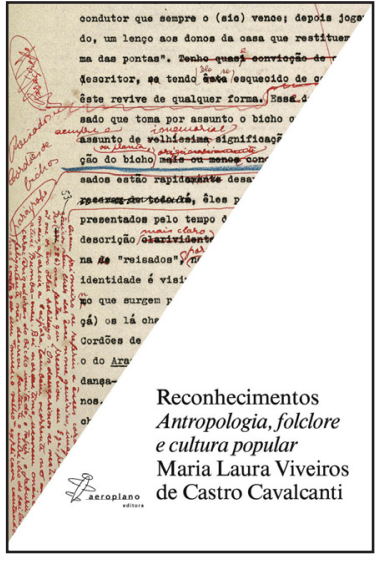

mento de Antropologia e do Programa de Pós-graduação em Sociologia e Antropologia da UFRJ, em que ingressa nos anos 90. Dentre seus ex-professores, destacam-se Gilberto Velho, que escreve a apresentação do livro, e Roberto DaMatta, ambos interlocutores privilegiados no conjunto de artigos apresentados. As preocupações próprias aos campos da antropologia urbana, dos rituais e da análise simbólica são bases teóricas e metodológicas recorrentes na produção da autora. A marca de um grupo de pesquisadores empenhados em contextualizar e apreciar os estudos de folclore no Brasil fica evidenciada nos artigos "Os estudos de folclore no Brasil", assinado por quatro autores, e "Traçando fronteiras: Florestan Fernandes e a marginalização do folclore", publicado em parceria com Luiz Rodolfo Vilhena. O livro é dedicado em memória a Vilhena e a Silvana Micelli de Araujo, colegas integrantes de uma geração de pesquisadores, da qual Cavalcanti faz parte, que viu nos estudos de folclore fonte crítica e dinâmica para a reflexão sobre o pensamento social brasileiro e sobre a chamada cultura popular brasileira.

Junto com a antropóloga, somos levados a apreciar a complexidade do campo de estudos de folclore e de sensibilidades a ele afeitas. A partir de reflexão crítica e respeitosa aos autores dessa época e à produção intelectual apresentada por uma geração 
de folcloristas marginalizada nas ciências sociais, Maria Laura constrói um caminho afetivo (marca importante dos estudos de folclore) com as pessoas e os temas apresentados. Sua maneira própria de elaborar questões e hipóteses logo no início dos artigos promove a leitura e a clareza dos argumentos. A essas qualidades somam-se o cuidado e a precisão no tratamento de documentos e fontes bibliográficas diversas, e sua sensibilidade etnográfica, seja o campo dos arquivos ou decorrente da observação direta e empírica.

Desse modo, Cavalcanti propõe percurso muito particular de compreensão da antropologia a partir da mediação entre tradições intelectuais e da contextualização de noções internas a esses campos, que também têm historicidade própria. Cavalcanti desempenha essa "missão" mesclando um pouco de si mesma, com discrição e elegância. Sua escrita é dinamizada pelos depoimentos pessoais sobre as pesquisas que realizou empiricamente, pela posição de admiradora de intelectuais mais distantes no tempo, como Mário de Andrade ou Oracy Nogueira, pela proximidade estabelecida com o professor DaMatta, ou, ainda, pela posição mais reflexiva sobre sua própria trajetória como no artigo "Por uma antropologia dos estudos de folclore. O caso do Maranhão".

No artigo "Origens, para que as quero? Questões para uma investigação sobre a umbanda" (cap. 1), a antropóloga nos leva a refletir sobre como as interpretações a respeito da umbanda/macumba, formuladas distintamente por Nina Rodrigues, Artur Ramos, Edison Carneiro e Roger Bastide, podem ser compreendidas como parte dos dilemas entre origens e continuidades que estruturam esse sistema simbólico afeito à incorporação de novos elementos. A autora indica que, passadas décadas, "o caráter heterogêneo da umbanda permanece", o que permitiria entendê-la como uma religião com forma particular, caracterizada pela heterogeneidade e fluidez (p. 64), pistas já indicadas em autores como Edison Carneiro e Bastide. No artigo "Os estudos de folclore no Brasil" (cap. 2), os autores apresentam o estado da arte dos estudos de folclore. O campo de constituição desses estudos é compreendido a partir da tradição europeia, com o prestígio dos antiquários nos séculos XVII e XVIII, e os trabalhos dos intelectuais românticos, associados à valorização das singularidades com raízes no século XIX. Tais bases sociais e ideológicas marcam presença na constituição do campo de estudos de folclore no Brasil. O corte temporal é marcado a partir de Sílvio Romero, fundador desses estudos segundo Edison Carneiro, até o surgimento da Comissão Nacional de Folclore, em 1947. No artigo "Traçando fronteiras. Florestan Fernandes e a marginalização do folclore" (cap.3), Vilhena e Cavalcanti, ao tratar do debate entre Florestan Fernandes e Edison Carneiro, apresentam ao leitor um quadro mais amplo de posições em um campo ainda em formação, cujas fronteiras eram ocupadas de forma mais fluida por sociólogos, antropólogos e folcloristas. O sociólogo Florestan Fernandes e o folclorista Edison Carneiro, este último engajado no Movimento Folclórico, demarcam dois caminhos distintos de pensamento e atuação quando os temas em foco são o folclore e as expressões populares. Suas trajetórias, formas de atuação, filiações institucionais e visões de mundo são constitutivas do que se consolidaria como um campo de estudos de teor mais sociológico, implementado nas universidades, e os estudos de folclore, cujo espaço de inserção afasta-se das univer- 
sidades e é construído em museus e institutos. Tais embates entre modelos de ciência e de conhecimento inscrevem diferentes projetos de modernização para o Brasil.

Sem encerrar os intelectuais de nosso pensamento social em escolas ou disciplinas, Cavalcanti demonstra seus trânsitos, arranjos institucionais, mediações e limitações. No artigo "Por uma antropologia dos estudos de folclore. O caso do Maranhão" (cap.4), a antropóloga destaca a correlação intelectual e institucional, no caso maranhense, entre os estudos de folclore e a institucionalização das ciências sociais. Ao relativizar a separação dessas duas áreas, a autora demonstra como os estudos de folclore configuram atualmente uma das vertentes que conformam a antropologia e a sociologia nas universidades no Maranhão. Outro viés problematizado sobre a constituição da antropologia pode ser vislumbrado no artigo "Oracy Nogueira: o estudo do estigma e do preconceito racial" (cap. 5). Cavalcanti coloca em perspectiva a biografia e trajetória institucional desse sociólogo-antropólogo, trazendo à luz algumas de suas pesquisas sobre estigma e preconceito, e valoriza a constituição de um campo de conhecimento em que a interlocução com temas e pesquisadores da Escola de Chicago, a dimensão etnográfica, o "aspecto humano dos dados", qualidade enfatizada por Donald Pierson, professor da Escola Livre de Sociologia e Política de São Paulo, convergem na produção original de Oracy em que pesa a dupla influência de uma sociologia empírica e da dimensão etnográfica. A trajetória de Oracy ajuda a compreender a influência intelectual própria do período 1940-1950 e a tensão nem sempre bem resolvida na vida pessoal do pesquisador entre a formação e definição de vocações e o meio institucional de uma época (p. 235).

A inspiração da obra de Roberto DaMatta na produção de Cavalcanti se evidencia na leitura cuidadosa do livro Carnavais, malandros e heróis. No artigo "Roberto DaMatta: o carnaval e a interpretação do Brasil" (cap.6), a autora demonstra como a análise de DaMatta é libertadora ao fornecer os instrumentos das teorias de rituais para o estudo do carnaval em consonância com a interpretação da sociedade mais ampla. O carnaval articula redes sociais amplas e diferenciadas e expressa a relação cotidiana e ritual na sociedade brasileira. Os carnavais interpretados por DaMatta servem de inspiração para pensar os dilemas da sociedade brasileira em torno dos sistemas de valores hierárquico e igualitário. No artigo que homenageia a socióloga Maria Isaura intitulado “Maria Isaura Pereira de Queiroz: seu gosto pelo folclore e pela cultura popular" (cap. 7), Cavalcanti aponta a perspectiva sócio-histórica que caracteriza o trabalho da socióloga, seu rigor e sua forte compreensão das expressões culturais. Em meio à apreensão do modo de vida social e dos grupos na cidade, Pereira de Queiroz entendeu a festa carnavalesca no contexto de suas transformações históricas e sociais.

O artigo "Cultura popular e sensibilidade romântica. As danças dramáticas de Mário de Andrade" (capítulo 8) indica que as visões de estudiosos sobre as expressões populares adentram o circuito dinâmico dos folguedos, festas e expressões, sendo apropriadas por tais expressões artísticas que, por sua vez, são reencarnadas na subjetividade de quem delas se aproxima. Nesse artigo, a autora depara-se com a ambivalência de Mário de Andrade em seu gosto pelas danças dramáticas em que o bumba meu boi ocupa lugar 
de destaque. $\mathrm{O}$ artigo que encerra o livro é "Tempo e narrativa nos folguedos do boi. A ilusão do arcaísmo nos estudos de folclore" (cap. 9). Nele, a autora coloca em perspectiva a crença compartilhada de que o bumba meu boi teria unidade dramática que permitiu a configuração do auto popular. A crença no auto do boi, cuja encenação se repetiria ao longo dos tempos, garantiria a continuidade do passado, coadunando-se com os princípios ideológicos românticos e com os ideais nacionais de modernidade, particularmente presentes nas formulações de Mário de Andrade. Ao fazer leitura compreensiva da unidade dramática do auto popular apresentada por muitos estudiosos, Cavalcanti oferece alternativa, uma nova chave de leitura em que a ênfase nas diversas narrativas de origem mítica do folguedo do boi compõem um conjunto de dramas e performances que arranjam elementos diversos, incluídos aqueles presentes nas narrativas dos estudiosos sobre os folguedos do boi, comprovando seu caráter vivo e dinâmico.

Os artigos podem ser lidos individualmente, permitindo ao leitor usufruir de algumas chaves para a leitura e a compreensão das tradições formadoras das ciências sociais. Em conjunto, eles permitem que o leitor conheça pouco a pouco, a partir de Cavalcanti, um modo sensível e afetivo de aproximação do universo do folclore e da cultura popular, de seus pensadores e de seus dilemas.

Esses textos alargam horizontes, destacam continuidades e revisam paradigmas. Desse modo, sua leitura nos serve como guia para explorar referências mencionadas, buscando outras continuidades e aprofundamentos. Reconhecimentos permite ao leitor adentrar o universo de reflexões da autora a partir de seu modo pessoal, caracterizado pela generosidade em destacar a consistência e a originalidade de autores ligados a tradições diversas. Reconhecemos, por fim, um estilo próprio de pensamento e de escrita fundamentados pela dedicação e pela delicadeza.

Renata de Sá Gonçalves é professora adjunta do Departamento de Antropologia da Universidade Federal Fluminense. 